sides over health and disease, are the sirens that won over Agassiz and Huxley and Helmholtz to their flowery realms. But just as zoölogy, chemistry, physiology, histology, are not the science of medicine, so neither is the science of medicine the same thing as the art of healing. To go hastily from the library of old books and the laboratory of new experiments to the bedside of disease is imitating the presumption of those rash profligates who, as Thomas Boston says, think they can take a "leap out of Delilah's lap into Abraham's bosom."

The medical student is in little danger now from the old theories which blinded the eyes of observers in former ages. He is more likely to forget his practical work, - which means giving his whole thought to the lesser as well as the greater needs of his patient, to all the little details of the sick-room, - in the fascinating pursuit of his scientific investigations. I would not undervalue the branch I teach. I recognize the incidental importance of all the subsidiary branches which form a part of the curriculum of this and other schools. Do full justice to them, or you will not probably do justice to your more immediately practical studies. But your hardest study must be at the bedside. Your real business will be to save life, to avert disease, to manage it so far as manageable, to save your patients all unnecessary suffering. And so doing may each of you be able to repeat the noble words of Thomas Sydenham, with which I will close this lecture. 'Two hundred years have passed since they were written, and they still speak in accents that can never grow old:-

"And, in truth, when I come to die, I trust I shall have the satisfaction of being inwardly assured that $I$ have not only endeavored, with the utmost diligence and integrity, to recover the health of all those who have been my patients, of whatever rank or condition they were, none of whom have been otherwise treated by me than I desire to be, if I should be seized by the same distempers; but also that I have contributed, to the utmost of my abilities, that the cure of diseases might, if possible, be prosecuted with greater certainty after my decease; being of opinion that any accession to this kind of knowledge, though it should teach nothing more pompous than the cure of the toothache, or corns, is of much greater value than all the vain parade of refinements in theory, and a knowledge of trifles, which are perhaps of as little service to a physician in removing diseases, as skill in musick is to an architect in building."

\section{Briginal Articles.}

$$
\begin{aligned}
& \text { CASES OF WRY NECK. } \\
& \text { BY E. H. BRADFORD, M. D., } \\
& \text { Surgeon to the Children's Hospital, Boston. }
\end{aligned}
$$

CASE I. L. T., nine years old. The patient presented herself for treatment, with the following history : Nine months before she was suddenly seized, without known cause, with pain in the head and neck. On the following morning her head was permanently drawn to one side. After a while the pain disappeared, but the distortion of the head remained the same.

The child's general condition was good, and she complained of no suffering or trouble in respiration; the position of the head was so fixed and the distortion was such that in walking in the street she occasionally ran into people, being unable to see them on account of the abnormal position of the face. From the line of the spinous processes in the cervical region it was evident that the spine was twisted to a marked degree. The head was movable to the right but not to the left. The muscles of the neck were not contracted, except the posterior muscles.

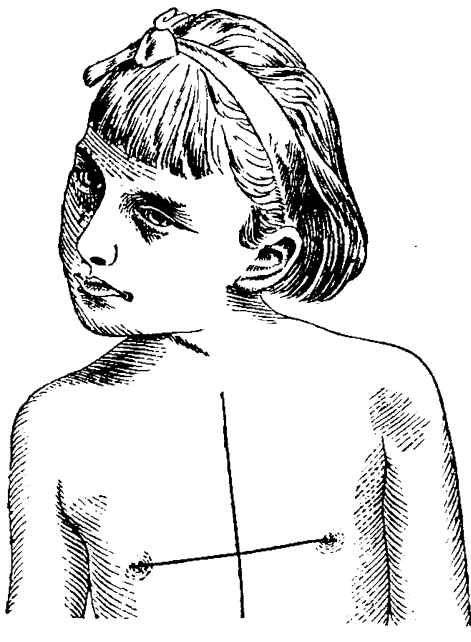

From photograph just before operation.

The patient was etherized, her shoulders were steadied by assistants, the head grasped between two hands placed on each side, and the deformity slowly rectified by manual force. The tendon of the sternomastoid was brought into prominence and divided by tenotomy, without evident advantage, however. Fibrous adhesions were felt to give way in the region of the spine, and after a time the axis of the face was brought in line with the axis of the trunk. It was found that a great deal of force would be required to correct the deformity, and it was not thought prudent to attempt this. In moving the head back toward the line of deformity it was felt to slip suddenly, as if returning to a position natural to the altered articular facets; on correction, however, the normal position was retained.

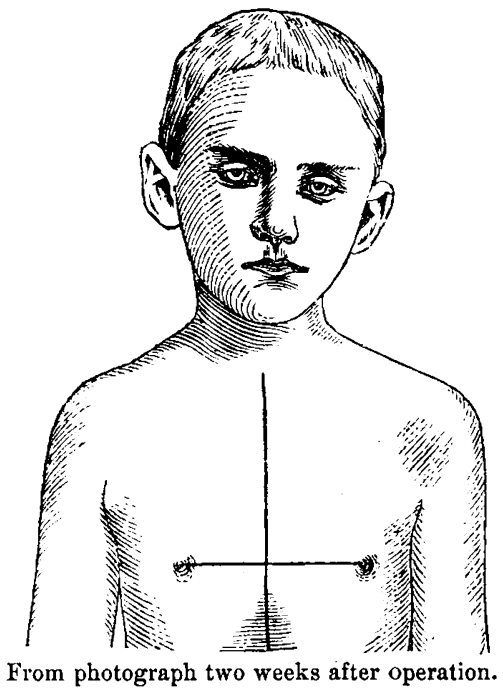

A plaster-of-Paris jacket was placed around the trunk, covering the shoulders, and a steel rod secured in it reaching above, and bent so as to partly encircle the head. Silicate-of-potash bandages fastened the 
head to the steel support and kept the axis of the face in the normal position. No disturbance followed the operation, and three weeks later the patient was again etherized, in order to gain, if possible, still farther motion in the neck to the left. But little, however, was accomplished in this direction.

The patient subsequently wore for three months a steel collar adapted so as to hold the head in a proper position, and since then has been without apparatus. At the present time, ten months after operative interference, the patient has shown no evidence of a relapse, the position of her head being that indicated in the picture. She has enjoyed the ordinary activity of children. Motion at the atlo-axoid articulation is perfect. Motion in the cervical spine below that is somewhat limited.

CASE II. H. ${ }^{1}$ The patient was a boy, nine years old, suffering from wry neck of three months' duration, which was said to have begun with pain and swelling behind the right ear. The face was turned to the right, and the left shoulder was raised higher than the right. Any attempt to turn the chin to the left of its position was unsuccessful and caused pain, but the chin could be moved farther to the right. 'The posterior muscles of the neck on the right side were hard on palpation. The sterno-cleido-mastoid muscles were flaceid.

After various unsuccessful attempts to correct the deformity by means of poultices, leeches, embrocations, and appliances, the boy was etherized, and the head placed in a normal position and fixed by the use of silieate-of-potash bandages, strengthened by a steel strip (holding the trunk and the head). The bandage was worn for a month. After its removal the head remained straight.

Two years later the boy was heard from, and reported to have remained without relapse.

CASE III. M. G., a girl nine years old, was affected with torticollis, the chin being turned to the left ; the right sterno-cleido-mastoid muscle was contracted, but there was no evidence of the implication of any other muscle. The deformity had come on gradually, and liad persisted for the past two years.

The patient was etherized, and the insertions of the sterno-mastoid muscle were divided. The head and trunk were immediately encased in a plaster-of-Paris bandage, firmly fixing the corrected position. In a week a modification of Mr. Swan's method (to be described later) was applied and worn for two months. There has up to the present time. five months after the operation, been no tendency to relapse.

Case IV. S. C., a boy six years old. This case resembled the preceding, except that the deformity is stated to have persisted since birth. A marked depression is to be found over the left eye in the frontal bone, which was said to be due to the blade of the forceps used at birth. The mother is led to attribute the deformity to this. The patient is perfectly healthy.

'Tenotomy of the sterno-mastoid was performed, and the head placed immediately in a corrected position, a plaster-of-Paris jacket being applied to the trunk, and adhesive plaster and straps applied to the head and, by means of buckles, fixing the correction. This appliance was worn six weeks. At the present time there has been no tendency to relapse.

Case V. K., delicate girl six years old, came under treatment for a slight distortion of the head, which had,

1 Vide New York Medical Journal, January, 1880. without known cause, persisted for six months; the chin was turned to the left, so that the axis of the face deviated from that of the trunk twenty degrees. The head could be turned in every other direction, but it was impossible to bring it to the normal position. The sterno-mastoid muscles were not affected, those at the back of the neck causing the deformity. One shoulder was held higher than the other, and a marked curve in the upper dorsal region of the spine was to be seen.

After four weeks' persistent treatment with various appliances, including, among others, the excellent arrangement of Dr. Shaffer, of New York, the head was brought to a normal position ; the motion becane perfect, and the curve in the back was corrected. No anæsthetic was used, the head being corrected by the use of apparatus alone.

The greatest amount of improvement was gained by the use of an appliance which supported the chin, and thereby took the strain caused by the weight of the head from the posterior muscles of the neck. This was readily accomplished by the wire collar of Dr. Buckminster Brown. The child wore this appliance for two months, to prevent relapse, and continued to be perfectly free from deformity after its discontinuance. At the present time, one year later, she is reported to be in perfectly normal position.

CASE VI. M., a gentleman, forty-five years of age, of exceedingly nervous temperament, who for many years was an active stock-broker in New York, was, on account of increasing nervousness, obliged to give up his business, which had been a prosperous one. He had been affected for some time with clonic spasm of the muscles of the neck, which twisted the chin to the right side. This was most noticeable when he walked, and at times his head remained perfectly straight. Steadying his head by applying a cane to the side of the face prevented the twisting of the head. A compensatory curve of the spine was noticed. Thorough treatment by the application of plaster-of-Paris appliances and section of the spinal accessory was declined.

Case VII. K., a woman twenty-eight years of age, of slight build and nervous temperament, became, without known cause, afflicted by a contraction of the muscles of the neck, which turned her head to the side, so that her chin was nearly above the right clavicle. This was most marked when the patient walked; some days it would be worse than others, and the deformity was worse as the patient was noticed or became nervous. Electricity and medical treatment were tried without benefit. Appliances were worn constantly for one month, and for three months regularly, which held the head in position, but no permanent benefit followed. Section of the spinal accessory or a plaster-of-Paris bandage was declined. The muscles most noticeably contracted were the posterior muscles in the neck; the sterno-mastoid muscles were not affected. ${ }^{2}$

CASE VIII. Healthy boy, nine years, whose sister had, one year before, been cured by tenotomy of a torticollis of several years' duration, was noticed by his parents to twist his head slightly. This gradually increased, and at the end of six months a marked persistent torticollis, with contraction of the right sternomastoid, was to be observed. No evidence of neuromimesis was to be noticed on watching the patient, and tenotomy is to be done.

2 For a similar case vide Boston Medical and Surgical Journal, A pril 27, 1882, page 396 . 
CASE IX. Healthy child, six weeks old, was brought for treatment with well-marked torticollis, the chin being turned to the right. This had appeared since birth, which had been a difficult one. On palpation the left sterno-mastoid was found to be ruptured three quarters of its entire width, the untorn fibres were spasmodically contracted. The child did not return for treatment.

Case X. A girl, ten years old, while in bed, after an attack of what was termed febricula, was pulled by the head, in play, by her sister, and on the following night suffered great pain in the head and side of the neck; the head was pulled to the side so that the ear rested nearly upon the shoulder. After a week a slight rectification of the deformity took place, and an enlarged gland could be felt in the region between the sterno-mastoid and the trapezius. The pain, which had been severe, suddenly disappeared, the tumor formed by the enlarged gland became larger, and fluctuation was felt, and incision advised, but not done. The swelling, however, was gradually absorbed, and the head slowly rectified itself, and at the end of three weeks the position and motion was perfectly normal, and has remained so for the past eight months. The sterno-mastoid muscle was not involved in this deformity. At the present time, six montbs after recovery, the patient has remained perfectly well.

CASE XI. A case seen in consultation with Dr. Doe, the patient being a woman of about twenty years of age, recovering from typhoid fever. The distortion was quite marked, and the head was well fixed in the distorted position by a spasm of the posterior muscles of the neck. Recovery slowly took place, the rectification occurring spontaneously.

CASE XII. P., healthy child, six months old, was

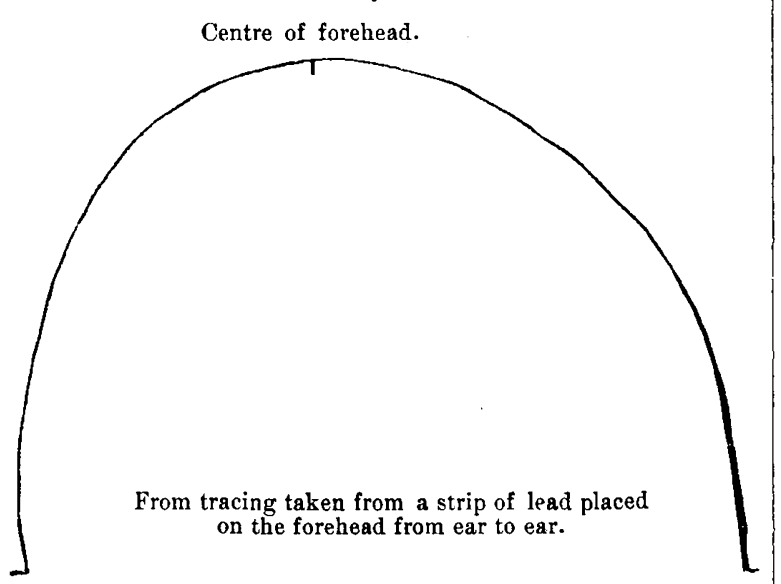

Left ear.

Right ear

born with a lack of symmetry of the cranium, affecting

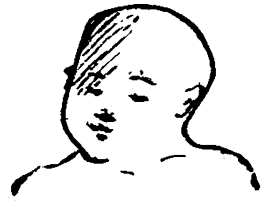
the frontal bone on the right side in such a way that from the orbital region upward the face appeared to be flattened, the frontal eminence, the supraorbital ridge, the malar bone being all less prominent on the right than the left side.

1 The face and head in every other Position usually as- respect was symmetrical. The child sumed by the child. appeared to be healthy, and was The shaded portion in- as intelligent as children of its age.
dicates the region of as diatening. The head was carried habitually in the position of wry neck, with the chin turned to the right, exactly in the position to suggest the explanation by the mother that the left side "was heavier than the right, and the head was held crooked." No paralysis existed, and the child could move the head in all directions voluntarily, no contraction being present. The usual position, however, was the one described; a slight secondary curvature of the spine was present, and in consequence the shoulders were held one higher than the other.

These cases illustrate the variety of causes ${ }^{1}$ which produce the deformity called wry neck, and also the fact, overlooked in many of the text-books, that the sterno-cleido mastoid muscle does not always play the most important part in the production of the deformity, a fact clearly shown by Delore, ${ }^{2}$ who claims that " posterior torticollis" is the more common form.

In wry neck from caries of the spine in the cervical region, the posterior muscles of the neck are those chiefly involved. Any irritation, however, at the base of the head will produce a similar deformity, as in Case II. and Case X. 'The distortion appears to be sometimes due to a neurosis, as in Cases III., VI., VII., and VIII. Of these three were affected in the sterno-mastoid alone, and two in the posterior muscles of the neck. In Case IV. a connection between the indentation of the skull and the wry neck is of course possible, but, in view of the facts presented by Case IX., hardly probable.

It would be difficult to class Case V. under any head unless that of a neurosis, and possibly Case XII. could be considered in the same way.

A variety of wry neck has been described by French writers as due to an inflammatory affection of the articulations in the cervical spine. It is possible that Case I. could be classed in this category. The patient had suffered from some process which affected the spinal column in the cervical region, as was evident from the fibrous adhesions, which gave way on rectifying the deformity. It might be otherwise considered a rare form of cervical caries where the process had undergone a spontaneous arrest after a short course. For nearly a year after the original seizure until the time of the operation no symptoms were present indicating caries, and up to the present time, ten months after operative interference, no evidence of caries is to be found.

The treatment employed in the cases which were treated was, in Cases I. and II., that advised by Delore, namely, rectification under an anæsthetic, and immediate fixation. Silicate of potash bandages recommended by him for fixation were used in Case II., but subsequent experience showed the advantage of plaster-ofParis. In Cases III. and IV. a modification of the arrangement described by Mr. Swan ${ }^{3}$ was used. This consists of a plaster-of-Paris jacket to hold the trunk and shoulder, into which buckles are fastened. A hold on the head is secured by applying the ordinary head bandage, encircling the bead from occiput to forehead, and from vertex to chin. As this would slip, a piece of rubber adhesive plaster is first applied on the forehead, and the beginning of the bandage is sewed to the end of the adhesive plaster. After the bandage is applied in the ordinary way it is to be stitched at the points of crossing, and webbing is sewn on at such

1 Cases of wry neck occurring in the ordinary course of cervical caries are not referred to in this paper.

2 Gaz. Hebd., March 15, 1878.

\& Dublin Journal Medical Sciences, August, 1879, page 114. 
places as will, when fastened to the buckles on the jacket encasing the trunk, twist the head in the direction desired. The exact places for the buckles and straps can be determined only by experimentation in each case. Perineal straps to hold the jacket from rising are of use.

As a portable appliance to be used as after-treatment to prevent relapse, the wire collar devised by Dr. Buckminster Brown leaves little to be desired.

REMARKABLE CASE OF SACCULATED OR OF CIRSOID ANEURISM OF THE SECOND IN'TEROSSEOUS BRANCH OF THE DEEP PALMAR ARCH TREATED BY EXCISION.1

\section{WITH EXHIBITION OF THE SPECIMEN.}

BY JOHN B. ROBERTS, M. D.

Lecturer on Anatomy and on Operative Surgery in the Philadelphia School of Anatomy.

THE specimen which I exhibit this evening and its accompanying history are interesting, I think, because of the extreme rarity of the condition. I know of no similar case reported; but I have not had an opportunity to search for such in medical literature, because the operation was performed only a few hours ago. The specimen is fresh, and is exhibited now before the appearances have been changed by any preservative fluid.

Dr. Charles H. Thomas requested me a few days ago to assist him, at an early date, in operating upon a tumor of the hand in a boy, aged sixteen years. From his earliest childhood he had been under Dr. Thomas's observation, and had had a small elongated tumor upon the dorsal surface of the first phalanx of the left ringfinger, while in the palm, at the junction of the bases of the middle and ring-fingers, was a larger swelling. 'These were considered masses of dilated veins, as they had a spongy feel, and at times showed a bluish color There was no very definite connecting band of swelling between the dorsal and palmar enlargements. No special pain was experienced unless the parts were struck, and no marked growth occurred. Hence the child's mother was advised to have nothing done. As the boy grew, the hand and tumor increased, but held the same relative proportions. When the boy began work in a machine-shop, the skin became thickened and soiled, and the bluish tint was no longer discernible.

About two months or less ago, the growths seemed to enlarge and to be accompanied by considerable pain, and Dr. Thomas advised the use of a compress in the palm and a bandage around the finger. This the boy wore at nights, and usually from Saturday to Monday morning when he returned to his work. Recently there was noticed pulsation in the palmar tumor and a lobulated feel ; and Dr. Thomas feared that an arterial aneurism existed.

When I examined the boy last evening, I found on the back of the third finger a hard fibrous-like tumor, as large as a watermelon seed, with the long diameter corresponding to the length of the phalanx. In the palm was an illy defined swelling covered with thick skin, very sensitive to pressure, and occupying about the area of a silver half-dollar. No swelling was evident connecting the two tumors. On the ulnar side of

1 Read May 3, 1882, before the College of Surgeons of Philadel phia. the palmar mass moderately distinct pulsation could be felt, which quickly stopped when the radial artery was compressed at the wrist, but merely decreased in force when the ulnar was pressed upon with the finger. No pulsation was felt in the dorsal tumor.

The boy had severe pain even when no pressure was made upon the growth in the palm.

I gave it as my opinion that the growth was an arterial angeioma connected with the second interosseous branch of the deep palmar arch, having anastomoses with the digital branches of the ulnar artery. Dr. Thomas considered it possibly this, but probably a sacculated aneurism. His diagnosis has proved to be the more correct.

It was determined to employ the Esmarch elastic bandage, and to make a free incision over the tumor and dissect it out, whether it be angeioma or aneurism. As Dr. 'Thomas was disabled by a painful boil on his right hand, be requested me to operate. The boy was etherized and the elastic bandage applied.

1 made an incision from a point a little in front of the superficial palmar arch to the commissure of the fingers, and came upon a mass of fat and small vessels, in the centre of which was a bluish nodule, resembling larger vessels containing blood not driven out by the elastic bandage. Keeping close to the skin, and going down to the sheaths of the flexor tendons, I dissected the mass free. Lying alongside of the palmar interosseous muscle going to the ring-finger (second interosseous) we saw a comparatively large vessel which seemed to be the main feeder of the mass. I then extended my incision, making a straight cut along the side of the ring-finger, dissected up the skin, and enucleated the hard nodule lying on the back of the first phalanx. This seemed connected with the other mass by some fibres or small vessels, and both were removed as one piece. The wound was then plugged with dry muslin to stop the general oozing that occurred after removal of the bandage, and a tight bandage applied. No ligatures were required, because my incisions were made at a distance from the tumor.

Dissection of the palmar mass showed that I had removed a small body, about three quarters of an inch in diameter, containing clotted blood, and surrounded by adipose tissue and nerves. Small collapsed vessels in large numbers may perhaps be found in this adipose tissue by microscopic examination. Only a few larger ones were recognizable by ocular inspection because of the absence of blood from the interior. The tumor, as is seen on the plate, consists of three lobules of rather unequal size, arranged somewhat as a trefoil. The largest one of them, which has been punctured, allows the escape of soft clot; this sac is about one half an iuch in diameter. 'The three sacs seem to be separate, because the head of a pin introduced into one does not pass into the others. The two smaller sacs or lobules are hard, as if the clot was old. One has been laid open, and shows a white centre, or nucleus, of cartilaginous consistence surrounded by a layer of red clot. On the surface of this three-lobed tumor runs a nerve, which probably was the seat of pain from pressure, and parallel to it a small artery. Both of these become lost in the mass, at the upper end of the tumor, which was thought to contain the main supply of the aneurism, and around which a string was tied and left for identification.

The tumor from the back of the finger is hard, and on section shows an irregularly colored red surface. 